\title{
Da saída do estado de natureza
}

\author{
On Rousseau's Second Discourse
}

\author{
Luís Fernandes dos Santos Nascimento \\ luisfsnascimento@yahoo.com.br \\ (Universidade Federal de São Carlos, São Paulo, Brasil)
}

\begin{abstract}
Resumo: A partir do Segundo Discurso, o presente texto busca analisar as complexidades presentes na ideia de estado de natureza apresentada na referida obra.
\end{abstract}

Palavras-chave: Rousseau; natureza; homem; história; moralidade.

\begin{abstract}
The present study has the purpose of analyzing, in Rousseau's Second Discourse, the importance of the notion of state of nature.
\end{abstract}

Keywords: Rousseau; nature; man; history; morality.

DOI: http://dx.doi.org/10.11606/issn.2318-9800.v22i3p69-75

Em um livro chamado $A$ borra do café, obra que mistura relato autobiográfico com ficção, o escritor uruguaio Mario Benedetti nos narra um episódio importante de sua vida. 0 trecho é um tanto longo, mas nos parece relevante citá-lo na íntegra:

Somente numa ocasião a Praia Capurro, em geral tão desprezada, se encheu de gente e de bicicletas. Foi quando veio o dirigível. 0 Graf Zeppelin. Aquela espécie de linguiça prateada, imóvel no espaço, pareceu admirável, quase mágica, a todo mundo adulto; para nós, em contraposição, era algo normal. Mais ainda: o espanto dos mais velhos nos parecia bobalhão. Ver todos eles de boca aberta, olhando para cima, nos provocava um riso tão contagioso que aos poucos foi se transformando numa gargalhada geracional. Os pais, tios, avós sentiram-se tão ofendidos por nossas risadas que os sopapos e beliscões começaram a chover sobre nossas frágeis anatomias. Uma injustiça histórica que nunca esqueceremos. Ainda assim, o Graf Zeppelin foi causa indireta de uma mudança importante em nossas vidas. Nosso interesse por aquele globo achatado e sem graça durou exatamente dez minutos. Quando começaram nossos primeiros bocejos, fomos nos retirando, ainda sem saber para onde encaminhar nossas expectativas. Os adultos continuavam boquiabertos, hipnotizados por aquela geringonça hermética, instalada no espaço aberto. De repente percebemos que naquele dia não existíamos, estávamos à margem do mundo, ao menos do mundo autorizado a se assombrar. De modo que, quando meu primo Daniel disse: "Somos livres!", todos tomamos consciência de que ele se tornara nosso porta-voz como também nosso líder” (Benedetti, 2012, pp.23-24, grifo nosso). 
Esse belo trecho de $A$ borra do café pode nos sugerir muitas questões. Tratase de uma passagem de uma primeira infância, ainda inocente, para a consciência que leva as crianças a adentrarem em um novo mundo: outro universo é aberto. Podemos dizer que a partir de agora elas já não mais habitam o domínio da inocência e são postas em um mundo moral, no qual se colocam como sendo seres livres. "Somos livres!" brada o primo do narrador. Podemos também nos perguntar acerca da importância da circunstância em que isso ocorre: se o Zeppelin não passasse pelos céus de Montevidéu, as crianças teriam sido despertadas para a consciência da liberdade? Uma vez acontecido, vemos que foi esse o evento que as fizeram abandonar esse primeiro estágio de suas vidas, no qual os pais eram respeitados e venerados. Mas, e se não houvesse o Zeppelin? Supõe-se que as crianças encontrariam outra ocasião na qual brotaria essa consciência, nelas ainda em potência. Como já sabemos que elas são capazes de tal proeza, o Zeppelin nele mesmo pode ser considerado como um mero pretexto. Qualquer outro evento poderia tomar o seu lugar. Podemos pensar que outra situação ou circunstância poderia ter o mesmo efeito sobre as crianças. 0 fato de ter sido o Zeppelin é, nesse sentido, casual. A grande linguiça prateada, como nos dizia o trecho acima, teria de ser vista como a ocasião que despertou nas crianças algo que nelas já era latente. Como se a capacidade de livrarse dos pais estivesse lá, apenas aguardando o momento certo para despertar. Tratase de uma mudança que não é física, não é o corpo das crianças que se transmuta, mas antes de uma mudança moral ou espiritual, que diz respeito a um novo modo de ver e perceber o mundo, ao mesmo tempo em que as faz entender algo do seu lugar neste mesmo mundo.

Embora o texto de Mario Benedetti não tenha nenhuma relação direta com Rousseau, podemos reconhecer aí uma semelhança com um tópico da filosofia do genebrino, a saber: assim como as crianças abandonam sua inocência, o homem foi capaz de sair do estado de natureza. E já não nos importa mais saber o que fez com que ele saísse (se foi algo como a visão dos adultos diante do Zeppelin ou outro fato extraordinário). 0 dado relevante é que o ser humano exerceu essa capacidade que o torna capaz de deixar um ambiente que lhe seria natural. 0 momento da saída se perde no tempo, pois ele mesmo é quem instaura o tempo. De acordo com o Segundo Discurso, o universo natural é um todo uno e completo. 0 ser natural vive em um eterno presente regido por uma ordem que é a da própria natureza: "Sua alma [a do homem natural], que nada agita, entrega-se unicamente ao sentimento da existência atual sem qualquer ideia do futuro, ainda que próximo, e seus projetos, limitados como suas vistas, dificilmente se estendem até o fim do dia" (Rousseau, 1988a, p.49).

Não há passado, tampouco futuro, assim como não há escolha ou liberdade. Se o homem pode se considerar como livre, ele já não está mais na esfera natural: 
A natureza manda em todos animais, e a besta obedece. 0 homem sofre a mesma influência, mas considera-se livre para concordar ou resistir, e é sobretudo na consciência dessa liberdade que se mostra a espiritualidade de sua alma, pois a física de certo modo explica o mecanismo dos sentidos e a formação das ideias, mas no poder de querer, ou antes, de escolher e no sentimento desse poder só se encontram atos puramente espirituais que de modo algum serão explicados pelas leis da mecânica (Rousseau, 1988a, p.47).

A consciência da liberdade, o fato de poder concordar ou discordar dos ditames da natureza, torna o homem um ser espiritual, distinto de todos os outros. Como sabemos, o Segundo Discurso condenará essa saída, vendo-a mais como uma degradação do que uma elevação do homem: "Se ela [a natureza] nos destinou a sermos sãos, ouso quase assegurar que o estado de reflexão é um estado contrário à natureza e que o homem que medita é um animal depravado" (Rousseau, 1988a, p.45).

O homem torna-se livre, passa a viver em outra ordem, na qual surgem a linguagem e a organização da vida em sociedade: "O verdadeiro fundador da sociedade civil foi o primeiro que, tendo cercado um terreno, lembrou-se de dizer isto é meu e encontrou pessoas suficientemente simples para acreditá-lo" (Rousseau, 1988a, p.63, grifo nosso).

Mas para dizer isto é meu, o homem teve antes de dizer eu, isto é: teve de ter consciência de si mesmo como sendo um agente livre. Foi circunscrevendo uma área que não é física, mas espiritual, que o homem pôde se diferenciar não apenas dos outros homens, mas também da natureza como um todo. Essa área é o espaço de sua egoidade. Sua primeira propriedade, aquilo que tem de mais próprio, é, antes de tudo, sua consciência como indivíduo.

Nesse novo universo, novas necessidades irão surgir: o homem que vivia solitário em seu estado de natureza, agora passa a ter a necessidade da vida comum. Todo o texto do Segundo Discurso nos mostra como foi difícil e penoso o processo no qual se organiza a vida social e o consequente afastamento da natural. O homem entra em um processo que é ilimitado, no qual novas invenções se sobrepõem às primeiras. A agricultura e metalurgia, citadas no Segundo Discurso, se inscrevem nesse processo em que o mundo das artes e das ciências se aperfeiçoam, como já nos dizia o Primeiro Discurso, texto no qual, afirmam os comentadores, já estava em germe a ideia de um estado de natureza, embora ainda não explicitada.

É bem conhecida a circunstância na qual a ideia que norteia o Primeiro Discurso surge. Roussseau, nos lembra François Bouchardy na introdução que escreve para o volume da Pléiade, a relata em várias ocasiões: em uma carta a Malesherbes de 12 de janeiro de 1762, no Livro VIII das Confissões, no Segundo Diálogo e na Terceira Caminhada dos Devaneios (Cf. Bouchardy, 1964, p.XXVII). Tudo começa quando Diderot é preso em julho de 1749 por “délit de presse" (idem, ibidem), 
acusado de ser o autor da Carta sobre os cegos, e é encarcerado no Castelo de Vincennes, próximo de Paris. Rousseau, então grande amigo de Diderot, costumava visitá-lo e fazia o percurso a pé. Foi nesse caminho que ele veio a saber do tema do concurso que a Academia de Dijon propunha para aquele ano. Estampada nas páginas do jornal Mercure de France estava a questão dirigida aos concorrentes, a saber: "O restabelecimento das ciências e das artes terá contribuído para aprimorar os costumes?".

Teria sido por mero acaso que Rousseau encontra o jornal e o tema ali exposto. Mas as circunstâncias, atenta Starobinski, desempenham um papel importante na obra de Rousseau. Se, por um lado, a narrativa do nascimento do Primeiro Discurso está carregada de elementos casuais, por outro, são essas mesmas circunstâncias que dão ocasião para algo que não é tão casual assim, isto é, uma certa disponibilidade que o autor já tinha para o tema, uma disposição que talvez nem ele conhecesse antes do momento em que ela se explicita, um pouco como o efeito causado nas crianças ao verem o espanto dos pais diante do Zeppelin. No caso de Rousseau, afirma Starobinski, foi o “encontro do gênio e da coerção” (Starobinski, 2006, p.330), circunstância na qual a disposição filosófica aflora intensamente, momento preciso no qual vem à tona certo talento. Rousseau vivenciou ali uma "iluminação", termo presente na já citada introdução de François Bouchardy (1964, p.XXVIII), que veio ao encontro de seus pensamentos. 0 tema da Academia não é senão o obstáculo que desperta em Rousseau a capacidade de transpô-lo. A ideia que o genebrino tem então é a de escrever o inverso do que comumente se pensa das artes e ciências, a saber: no lugar de tornarem os homens mais virtuosos, elas antes os corrompem. Não só as artes e as ciências corrompem o homem, mas também e, sobretudo, a sociedade na qual elas são criadas e onde elas se mantêm. Embora ainda não apareça aqui explicitamente a noção de estado de natureza, tal como será elaborada no Segundo Discurso, a crítica à sociedade se faz presente por oposição ao que o Primeiro Discurso chama de virtude. Essa ideia permeará quase todos os textos do filósofo.

O mesmo processo pode ser contemplado a partir do tema da linguagem: o homem natural nada diz. Se ele se comunica é tal como os animais que não o fazem senão para satisfazer necessidades estritamente naturais. No Ensaio sobre a origem das línguas, Rousseau afirma que a primeira linguagem nasce de uma necessidade que já é moral, que quer tocar o outro, movimento que exige, portanto, a consciência de um semelhante, mas também a consciência de si mesmo como sendo um ser livre, que escolhe e que quer, que tem desejos e que, portanto, possui carências, coisa estranha aos seres que vivem plenamente no estado de natureza. A primeira linguagem, diz-nos o Ensaio sobre a origem das línguas, não era distinta da música. As primeiras palavras teriam sido cantadas, próximas das paixões que as impulsionavam. Aos poucos, devido às necessidades morais, as palavras começam a se diferenciar, 
a ganhar sentidos precisos a ponto de começarem a descrever coisas abstratas, que não existem na natureza. Por sua vez, a música se torna cada vez mais harmônica e menos melódica, afastando-se da paixão que havia lhe suscitado. A música torna-se um estudo de harmônicos e a linguagem é pautada pela gramática. O exemplo das línguas e da música nos parece importante, pois ilustra como no mundo social as coisas não param de se desenvolver e se aperfeiçoar:

é a faculdade de aperfeiçoar-se, faculdade que, com auxílio das circunstâncias, desenvolve sucessivamente todas as outras e se encontra, entre nós, tanto na espécie quanto no indivíduo; o animal, pelo contrário, ao fim de alguns meses, é o que será por toda a vida, e sua espécie, no fim de milhares de anos, o que era no primeiro ano desses milhares" (Rousseau, 1988a, p.47, grifo nosso).

$\mathrm{Na}$ continuidade do texto que acabamos de citar, Rousseau irá se perguntar: "Por que só o homem é suscetível de tornar-se imbecil?" (idem, ibidem). A questão é a de saber por que o homem, e somente ele, é suscetível de mudanças, podendo se mover em um universo que não é mais aquele que rege toda a vida animal e natural. 0 ponto não é saber quais foram exatamente as circunstâncias que levaram o homem a tais e tais comportamentos, mas o fato de ele ser suscetível a essas circunstâncias.

Um pouco mais abaixo, ainda no mesmo Segundo Discurso, Rousseau falará da perfectibilidade como traço determinante do homem que já não mais habita a natureza. As belas artes e as ciências também fazem parte desse processo, como nos mostra o Primeiro Discurso: sua evolução é também um afastamento frente à ordem natural, que sempre permanece a mesma, una e simples. Já a ordem social é multifacetada: ao longo do tempo várias leis podem surgir, assim como vários costumes e línguas podem aparecer. É o mundo social que distingue os homens, não apenas uns dos outros, como dissemos, mas dele mesmo - cada indivíduo separa-se do que nele era uma natureza una e completa. O homem social é um ser cindido que busca por vários meios reestabelecer a harmonia perdida, mas ao buscá-la, o faz com ferramentas e artifícios que já são estranhos à natureza e, assim, no lugar de voltar ao universo natural, afasta-se cada vez mais dele. A linguagem e as leis civis acabam por criar novos obstáculos, para empregar um termo consagrado por Starobinski, e suscitam novos avanços e aperfeiçoamentos. Toda tentativa de ajustar as diferenças e buscar um universo harmônico já é feita em um âmbito que, desde seu princípio, é avesso à harmonia natural. Toda sociedade, por mais justa que seja, ainda é desigual, pois está fundada sob o signo da diferença, de uma desigualdade que, como vimos, não é somente de um homem em relação a outro, mas do homem em relação a si mesmo, em relação a sua própria natureza.

Visto por esse prisma, o diagnóstico que o Segundo Discurso nos apresenta é bastante pessimista, uma vez que toda instituição social que busca a resolução de algum mal acaba por criar outros males ainda piores do que os primeiros, como o 
médico que ao empregar o remédio sabe dos efeitos colaterais que ele pode causar. Mas o tema muda de figura se considerarmos o que é afirmado no Prefácio desta obra, local em que Rousseau afirma que o estado de natureza é um "estado que não mais existe, que talvez nunca tenha existido, que provavelmente jamais existirá, e sobre o qual se tem, contudo, a necessidade de alcançar noções exatas para bem julgar de nosso estado presente" (Rousseau, 1988a, pp.32-33, grifo nosso). O leitor do Segundo Discurso é posto então diante de um paradoxo: se, de um lado, o estado de natureza é tudo aquilo que representa uma oposição frente ao artifício que é a sociedade, agora ele também parece como fruto de uma imaginação - desse ponto de vista, tão artificial quanto qualquer instituição social. Ele é, como sugere Salinas Fortes em seu Paradoxo do espetáculo, algo como uma ideia reguladora que nos auxilia a julgar o estado presente do homem ${ }^{1}$. É a necessidade de entender o surgimento e o desenvolvimento do mundo social que exige a "criação" da ideia de um estado anterior a ele. É a busca por uma origem ou por este elemento original que legitima tal recurso. Não é à toa que Rousseau emprega tanto termos como "suponhamos", "imaginemos" - a história que ele nos conta tem de ser entendida como conjectural e não factual e exige um leitor que tenha consciência disso: “Oh! Homem, de qualquer região que sejas", escreve Rousseau em um trecho célebre do Segundo Discurso, "quaisquer que sejam tuas opiniões, ouve-me; eis tua história como acreditei tê-la lido não nos livros de teus semelhantes, que são mentirosos, mas na natureza que jamais mente" (idem, p.41).

Mas essa natureza, tão necessária para a compreensão do homem, é ela mesma uma ideia à qual devemos recorrer e aceitar para entendermos o problema da origem da sociedade. "Não poderei formular sobre esse assunto senão conjeturas vagas e quase imaginárias", escreve Rousseau (1988a, p.41) no início da Primeira Parte do Segundo Discurso. A saída do estado de natureza não poderia ser senão conjetural, pois, como vimos, ela mesma se faz em uma ocasião que não é possível apreender, em um momento em que o próprio tempo, em geral tão importante para o historiador, acaba de começar.

\section{Referências}

Benedetti, M. (2012). A borra do café. Tradução de Joana Angélica d'Avila Melo. Rio de Janeiro: Objetiva.

Bouchardy, F. (1964). Introduction (Discours sur les sciences et les arts). In: Rousseau, J.-J. Oeuvres complètes (p.XXVII-XLI). Vol. III. Paris: Bibliothèque de la Pléiade.

Fortes, L.R.S. (1997). Paradoxo do espetáculo. São Paulo: Discurso Editorial.

\footnotetext{
1 É Luiz Roberto Salinas Fortes (1997, p.97) quem afirma: “Mas o que é afinal a 'Natureza'? Ora, é bem provável tratar-se de uma simples ideia reguladora - como a ideia de Deus, em Kant - que orienta nossas observações, mas à qual não somos capazes, dada nossa finitude, de atribuir um conteúdo efetivo".
} 
Prado Jr., B. (2008). A retórica de Rousseau. São Paulo: Cosac Naify.

Rousseau, J-J. (1964). Oeuvres complètes. Vol. III. Paris: Bibliothèque de la Pléiade. . (1988a). Discurso sobre a origem e os fundamentos da desigualdade entre os homens. Tradução de Lourdes Santos Machado. São Paulo: Nova Cultural. - (1988b). Discurso sobre as ciências e as artes. Tradução de Lourdes Santos Machado. São Paulo: Nova Cultural.

. (2008). Ensaio sobre a origem das línguas. Tradução de Fulvia M.L. Moretto. Campinas: Editora da UNICAMP.

Starobinski, J. (2006). Jean-Jacques Rousseau: la transparence et l'obstacle. Paris: Gallimard.

Gallimard.

(2012) Accuser et séduire - Essais sur Jean-Jacques Rousseau. Paris:

Recebido em: 29.08.2016

Aceito em: 20.11.2016 